\title{
Model Reactions Involving Ester Functional Groups during Thermo-Oxidative Degradation of Biodiesel
}

\author{
James C. Ball $^{1}$ (i) $\cdot$ James E. Anderson $^{1}$ (i) $\cdot$ Victoria A. Sears $^{1,2} \cdot$ Timothy J. Wallington $^{1}$ (ib
}

Received: 1 March 2019 / Revised: 8 July 2019 / Accepted: 17 July 2019

(C) 2019 AOCS

\begin{abstract}
Biodiesel is a renewable fuel used in diesel engines that is typically blended with diesel fuel. However, biodiesel is susceptible to oxidation, which has the potential to produce higher molecular weight materials that may adversely impact vehicle fuel-system performance. To investigate the chemical reactions potentially important in biodiesel oxidation, four different types of chemical reactions involving esters were studied: (1) ester formation (reactions of acids with alcohols), (2) alcoholysis (reactions of alcohols with esters), (3) acidolysis (reaction of acids with esters), and (4) ester exchange (reactions between two esters). Experiments with representative model compounds were used to evaluate these reactions at $90^{\circ} \mathrm{C}$ with aeration; conditions previously used to simulate thermooxidative degradation during biodiesel aging. Reactions were monitored using gas chromatography, fourier transform infrared (FTIR) spectroscopy, and total acid number (TAN). Evidence is presented suggesting that alcoholysis and ester formation (Reactions 1 and 2), catalyzed by carboxylic acids, are important reactions of esters that could lead to larger molecules. Acidolysis (Reaction 3) proceeded at a comparatively slow rate and ester exchange reaction
\end{abstract}

Supporting information Additional supporting information may be found online in the Supporting Information section at the end of the article.

James E. Anderson jander63@ford.com

1 Research \& Advanced Engineering, Ford Motor Company, Dearborn, MI 48124, USA

2 Department of Mechanical Engineering, University of MichiganDearborn, Dearborn, MI 48128, USA products (Reaction 4) were not detected under these aging conditions.

Keywords Ester group $\cdot$ Reactions of esters - Biodiesel oxidation $\cdot$ Model reactions

J Am Oil Chem Soc (2019) 96: 1153-1161.

\section{Introduction}

Biodiesel is a renewable fuel for compression ignition (diesel) engines that is typically blended with petroleum diesel at concentrations up to $20 \%$ by volume. Biodiesel production involves the chemical conversion of plant oils and animal fats (triacylglycerols of typically 16- and 18 carbon fatty acids) into individual fatty acid methyl esters (FAME), which reduces viscosity and improves cold temperature performance. While the cetane number, lubricity, and soot-forming tendency of biodiesel are attractive relative to petroleum diesel (Knothe et al., 2005), biodiesel is susceptible to oxidation with potentially adverse impacts on fuel quality and engine and fuel system performance (Knothe et al., 2005; Waynick, 2005).

Biodiesel includes FAME of both saturated and unsaturated fatty acids. Oxidation susceptibility is closely related to the content of polyunsaturated FAME and secondarily to monounsaturated FAME. Oxidation reactions are initiated by reactive oxygen species at carbon atoms adjacent (allylic) to double-bonded carbon atoms (Knothe et al., 2005; Waynick, 2005). A sequence of radical reactions including hydrogen abstraction, molecular oxygen addition, and intramolecular isomerization leads to a range of oxygenated products with a variety of functional groups. Higher molecular weight materials formed in these reactions increase the viscosity of the 
fuel and can lead to deposits in the engine (Fang and McCormick, 2006). The reaction pathways and rates vary with temperature (Waynick, 2005).

In earlier studies, we monitored biodiesel oxidation at $90^{\circ} \mathrm{C}$ with aeration, characterized the impact of the resulting thermo-oxidative degradation on fuel composition and properties, and subsequently chemically characterized the resulting higher molecular weight products (Ball et al., 2018a, b; Østerstrøm et al., 2016). These experiments confirmed that compounds with new ester linkages (polyester polymers) were significant contributors to the high molecular weight products and the increased viscosity. Saturated FAME (methyl stearate and methyl palmitate), which do not contain double bonds, were observed to oxidize to a limited extent (Østerstrøm et al., 2016) even though saturated FAME are generally thought to be considerably less reactive under these conditions (Knothe et al., 2005; Waynick, 2005).

Four different chemical reactions involving ester functional groups are noted in the literature (Barkenbus et al., 1940; Formo, 1954; Koskikallio, 1969; Wright et al., 1944):

1. Ester formation (reactions of carboxylic acids with alcohols),

2. Alcoholysis (reactions of alcohols with esters),

3. Acidolysis (reactions of carboxylic acids with esters), and

4. Ester exchange (reactions between two esters).

However, the potential involvement and relevance of these reactions have not been investigated for the oxidizing conditions found in diesel fuel systems (elevated temperature and aeration). To address this, a series of experiments were conducted to explore the significance of these reactions under such conditions using model compounds representative of biodiesel and biodiesel oxidation products.

\section{Experimental Procedures}

Soybean methyl ester (SME) biodiesel without added antioxidants was obtained from Gage Products (Ferndale, MI, USA). The biodiesel fuel was oxidized by heating in glass tubes at $90^{\circ} \mathrm{C}$ while aerating with $100 \mathrm{~mL} \mathrm{~min}{ }^{-1}$ dry air as described previously (Ball et al., 2018a, b; Østerstrøm et al., 2016). Sample tubes were covered by glass condenser caps fed with $20^{\circ} \mathrm{C}$ chilled water to reduce evaporative losses. Properties of the SME biodiesel are shown in Table S1 of Supporting Information. Individual FAME, alcohols, and reagents were obtained from commercial sources (Fischer Scientific, Pittsburgh, PA, USA).

Decyl decanoate was prepared by reacting decanoyl chloride with a $10 \%$ molar excess of decanol at $100{ }^{\circ} \mathrm{C}$ for
12 hours followed by vacuum distillation to remove unreacted material. The decyl decanoate product was verified by fourier transform infrared (FTIR) spectroscopy against a reference spectrum (Sdbsweb, 2018). Hexadecyl stearate was prepared by reacting an equimolar concentration of hexadecanol with stearoyl chloride and heating at $80^{\circ} \mathrm{C}$ for 2 hours. This product was used without further purification to identify the GC-FID peak elution time of hexadecyl stearate.

Decanol, decyl decanoate, and other esters were quantified using gas chromatography with flame ionization detection (GC-FID). The GC was equipped with a Restek Rxi5HT column $(30 \mathrm{~m} \times 0.320 \mu \mathrm{m} \times 0.25 \mu \mathrm{m})$ and used with the following parameters: inlet temperature $380^{\circ} \mathrm{C}$; initial temperature $110^{\circ} \mathrm{C}$, held for $1 \mathrm{~min}, 5.0^{\circ} \mathrm{C} \mathrm{min}{ }^{-1}$ ramp to $390^{\circ} \mathrm{C}$, and held at $390^{\circ} \mathrm{C}$ for $15 \mathrm{~min} ; 1 \mathrm{~mL} \mathrm{~min}{ }^{-1} \mathrm{He}$ carrier gas flow; 20:1 split ratio; and $1.0 \mu \mathrm{L}$ injection volume. Samples were diluted in dichloromethane prior to injection.

Experiments using model compounds were conducted using the same experimental conditions used in previous biodiesel aging studies $\left(90^{\circ} \mathrm{C}\right.$ with $100 \mathrm{~mL} \mathrm{~min}^{-1}$ dry air) (Ball et al., 2018a, b; Østerstrøm et al., 2016). Ester formation was evaluated by studying the reaction of decanol and decanoic acid. Alcoholysis of esters was evaluated by studying the reaction of hexadecanol and methyl stearate at equimolar concentrations, and again with hexadecanol, methyl stearate, and methyl linoleate at a 1.0:1.0:0.2 M ratio. Acidolysis of esters was evaluated by studying the reaction of methyl palmitate and stearic acid at equimolar concentrations. Ester exchange reactions were evaluated by studying the reaction of ethyl palmitate and methyl stearate at equimolar concentrations. Model compounds and their boiling points are provided in Table 1 . Vapor pressures are available in Table S2. The progress of the reactions was generally monitored by quantifying product and reactant concentrations by GC-FID. Decanoic acid was quantified using FTIR spectroscopy with attenuated total reflectance at $1670 \mathrm{~cm}^{-1}$ using a Thermo Scientific Nicolet iS $10 \mathrm{spec}$ trometer equipped with a Smart ARK accessory. Total acid number (TAN) was determined by titration with $0.5 \mathrm{~N}$ KOH using AOCS Method Cd 3d-63 (Sallee et al., 2004).

\section{Results and Discussion}

In our previous studies of biodiesel oxidation, saturated FAME were observed to be slowly, but steadily, oxidizing during experiments at elevated temperature $\left(90^{\circ} \mathrm{C}\right.$ with aeration) (Ball et al., 2018a; Østerstrøm et al., 2016). An example for $100 \%$ soybean biodiesel oxidation is shown in Fig. 1. Polyunsaturated FAME (methyl linolenate, 18:3, and methyl linolenate, 18:2) oxidized quickly while 
Table 1 Model reactants and products

\begin{tabular}{|c|c|c|c|c|c|}
\hline Compound name & Common name & $\begin{array}{c}\text { Reactant }(\mathrm{R}), \\
\text { product }(\mathrm{P})\end{array}$ & CAS number & Formula & $\begin{array}{c}\text { Boiling point } \\
{ }^{\mathrm{a}} \\
\left({ }^{\circ} \mathrm{C}\right), 1 \mathrm{~atm}\end{array}$ \\
\hline Water & Water & $\mathrm{P}$ & $7732-18-5$ & $\mathrm{H}_{2} \mathrm{O}$ & 100 \\
\hline Methanol & Methanol & $\mathrm{P}$ & $67-56-1$ & $\mathrm{CH}_{4} \mathrm{O}$ & 65 \\
\hline$n$-decanol & Decanol & $\mathrm{R}$ & $112-30-1$ & $\mathrm{C}_{10} \mathrm{H}_{22} \mathrm{O}$ & 230 \\
\hline$n$-decanoic acid & Decanoic acid & $\mathrm{R}$ & $334-48-5$ & $\mathrm{C}_{10} \mathrm{H}_{20} \mathrm{O}_{2}$ & 270 \\
\hline$n$-hexadecanol & Hexadecanol & $\mathrm{R}$ & $36653-82-4$ & $\mathrm{C}_{16} \mathrm{H}_{34} \mathrm{O}$ & 325 \\
\hline$n$-hexadecanoic acid & Palmitic acid & $\mathrm{P}$ & $57-10-3$ & $\mathrm{C}_{16} \mathrm{H}_{32} \mathrm{O}_{2}$ & 350 \\
\hline$n$-hexadecanoic acid, methyl ester & Methyl palmitate & $\mathrm{R}, \mathrm{P}$ & $112-39-0$ & $\mathrm{C}_{17} \mathrm{H}_{34} \mathrm{O}_{2}$ & 325 \\
\hline$n$-hexadecanoic acid, ethyl ester & Ethyl palmitate & $\mathrm{R}$ & $628-97-7$ & $\mathrm{C}_{18} \mathrm{H}_{36} \mathrm{O}_{2}$ & 242 \\
\hline$n$-octadecanoic acid & Stearic acid & $\mathrm{R}$ & $57-11-4$ & $\mathrm{C}_{18} \mathrm{H}_{36} \mathrm{O}_{2}$ & 374 \\
\hline $\begin{array}{l}\text { cis-9, cis-12-octadecadienoic acid, } \\
\text { methyl ester }\end{array}$ & Methyl linoleate & $\mathrm{R}$ & $112-63-0$ & $\mathrm{C}_{19} \mathrm{H}_{34} \mathrm{O}_{2}$ & 346 \\
\hline$n$-octadecanoic acid, methyl ester & Methyl stearate & $\mathrm{R}, \mathrm{P}$ & $112-61-8$ & $\mathrm{C}_{19} \mathrm{H}_{38} \mathrm{O}_{2}$ & 351 \\
\hline$n$-octadecanoic acid, ethyl ester & Ethyl stearate & $\mathrm{P}$ & $111-61-5$ & $\mathrm{C}_{20} \mathrm{H}_{40} \mathrm{O}_{2}$ & 356 \\
\hline$n$-decanoic acid, $n$-decyl ester & Decyl decanoate & $\mathrm{P}$ & $1654-86-0$ & $\mathrm{C}_{20} \mathrm{H}_{40} \mathrm{O}_{2}$ & $362^{\mathrm{b}}$ \\
\hline $\begin{array}{l}n \text {-hexadecanoic acid, } \\
n \text {-hexadecyl ester }\end{array}$ & Hexadecyl palmitate & $\mathrm{P}$ & $540-10-3$ & $\mathrm{C}_{32} \mathrm{H}_{64} \mathrm{O}_{2}$ & $534^{\mathrm{b}}$ \\
\hline $\begin{array}{l}n \text {-octadecanoic acid, } \\
n \text {-hexadecyl ester }\end{array}$ & Hexadecyl stearate & $\mathrm{P}$ & $1190-63-2$ & $\mathrm{C}_{34} \mathrm{H}_{68} \mathrm{O}_{2}$ & $528(\text { est })^{\mathrm{b}}$ \\
\hline
\end{tabular}

${ }^{\text {a }}$ Data from 2018 DIPPR $^{\circledR}$ Evaluated Database ${ }^{\circledR}$, unless otherwise noted, and published with permission of AIChE ${ }^{\circledR}$.

$\mathrm{b}$ TGSC database (2018).

monounsaturated methyl oleate (18:1) oxidized more slowly, as expected. However, the concentrations of the two saturated FAME (methyl stearate, 18:0, and methyl palmitate, 16:0) also declined, albeit very slowly, which was not expected. Chemical or physical mechanisms leading to their removal were not characterized, but it was hypothesized that saturated esters might undergo oxidation reactions on the alkyl chain via thermal degradation or attack by free radicals generated from oxidation of the unsaturated FAME.

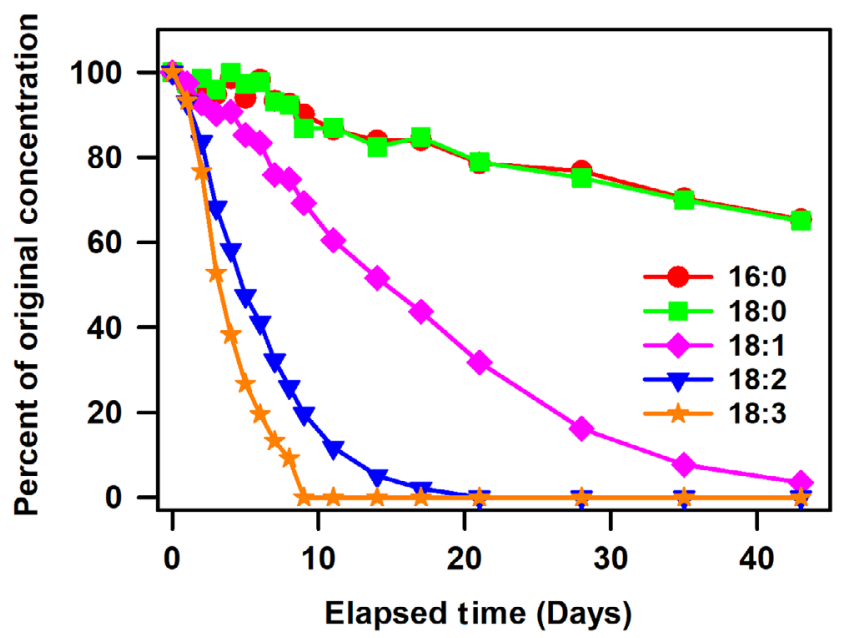

Fig. 1 Percent of initial FAME concentration for soybean biodiesel oxidized at $90^{\circ} \mathrm{C}$ with aeration. Reprinted (adapted) with permission from Ball et al. (2018a), Copyright (2018), American Chemical Society.
Three reactions were identified that could have contributed to FAME removal and potentially to formation of larger molecules leading to increased viscosity: alcoholysis (reaction of an alcohol with an ester), acidolysis (reaction of an acid with an ester), and ester exchange (reactions between two esters) (Barkenbus et al., 1940; Formo, 1954; Koskikallio, 1969; Wright et al., 1944). These reactions and ester formation by reaction of acids with alcohols were investigated through experiments using model compounds. The commercially available model compounds chosen were intended to (1) be representative of biodiesel and biodiesel oxidation products (10- and 18-carbon fatty acids, esters, and alcohols), (2) have sufficiently low vapor pressure to be adequately retained in the experimental system, and (3) have products with boiling points sufficiently low to be measured by GC (Table 1). Each of these reactions could potentially be driven to product formation if one of the products was of sufficiently low molecular weight that it would be stripped from solution as it formed. For example, acetic acid, methyl butyrate, and methanol have vapor pressures similar to or greater than water $(40,68$, and $255 \mathrm{kPa}$, respectively, vs. $70 \mathrm{kPa}$ for water) at $90^{\circ} \mathrm{C}$; water is readily stripped in these experiments.

\section{Ester Formation}

Ester formation during the thermo-oxidative degradation of SME biodiesel was indicated previously through several 
lines of evidence, including an overall increase in ester content (Ball et al., 2018a). In our previous study, ester formation from alcohol and acid oxidation products were proposed to explain the observation that ester content steadily increased and comprised $40-60 \%$ of the incorporated oxygen for biodiesel-containing fuels aged under these conditions. The ester products were hypothesized to form from reaction of carboxylic acids and alcohols, both of which are known biodiesel oxidation products (Chuck et al., 2012; Waynick, 2005; Wexler, 1964). The formation of carboxylic acids is likely due to the oxidation of aldehydes and ketones that are present as secondary degradation products from the oxidation of the FAME. Alcohols are likely generated through hydrogen abstraction from alkoxy radicals during FAME oxidation. Carboxylic acids and alcohols form esters and water in a reversible equilibrium reaction (Morrison and Boyd, 1992). The aging conditions $\left(90^{\circ} \mathrm{C}\right.$ with aeration) continuously remove water, which drives the equilibrium toward ester formation. The example in Reaction 1 shows compounds with both alcohol and carboxylic acid functional groups (hydroxycarboxylic acid) being linked by a new ester bond. The product is another hydroxycarboxylic acid that could continue to react to generate a larger polyester. The hydroxycarboxylic acid would likely be formed from an alkoxy carboxylic acid formed during the oxidation of a FAME. The alkoxy radical would abstract a hydrogen from another hydrocarbon or water to generate a hydroxycarboxylic acid. Such polyfunctional compounds (e.g., dicarboxylic acids, dialcohols, and hydroxycarboxylic acids) could act as cross-linking reactants. Dicarboxylic acids have been detected as products of biodiesel oxidation and from depolymerization of higher molecular weight oxidation products under the thermooxidative aging conditions used in the present study (Ball et al., 2018a; de Carvalho et al., 2016; Wexler, 1964).

To test the underlying hypothesis that long-chain carboxylic acids and alcohols could have reacted to generate new esters in the prior biodiesel aging studies (Ball et al., 2018a, b), an experiment was conducted allowing decanol and decanoic acid (each at $50 \mathrm{~mol} . \%$ concentration) to react under the same conditions $\left(90^{\circ} \mathrm{C}, 100 \mathrm{~mL} \mathrm{~min}^{-1}\right.$ dry air). The expected ester product, decyl decanoate, was formed rapidly in the expected stoichiometric amount as the two reactants disappeared (Fig. 2). The slightly greater removal of decanol relative to decanoic acid, despite a 1:1 stoichiometric reaction and equimolar initial concentrations, may

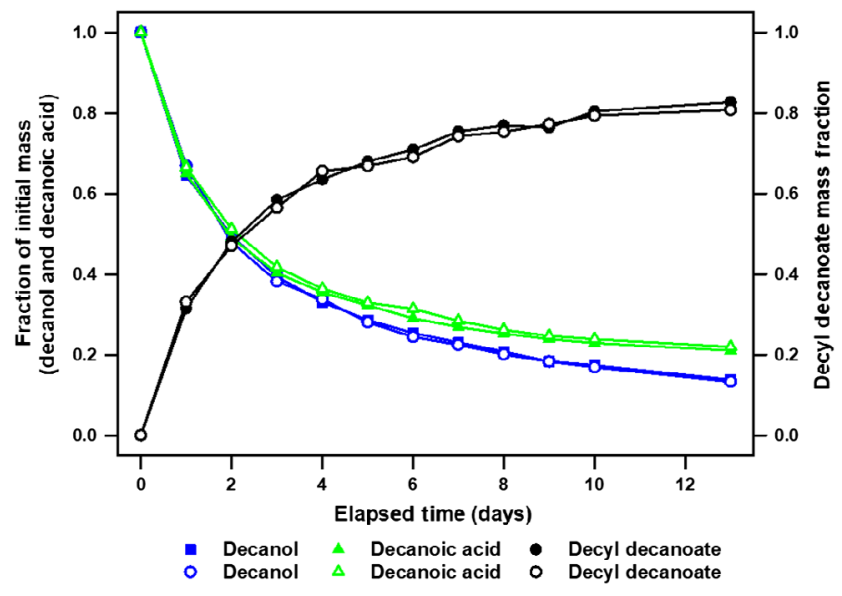

Fig. 2 Ester formation reaction of decanoic acid and decanol initially at equimolar concentrations, reacting to form decyl decanoate, at $90^{\circ} \mathrm{C}$ with aeration. Results for duplicate experiments are shown as open and filled symbols

be due to volatile loss of decanol. The boiling point of decanol is considerably lower than that of decanoic acid (Table 1) and its vapor pressure is correspondingly higher (Table S2). As such, decanol is susceptible to volatile losses due to continuous aeration, though mitigated by the presence of a water-cooled chiller. The relatively short time scale in which this ester-forming reaction occurred (2 days for $50 \%$ reaction) demonstrates that esters could be formed from alcohols and carboxylic acids generated during the biodiesel aging studies, which were up to 43 days in duration.

\section{Alcoholysis}

Alcoholysis involves the equilibrium reaction of an alcohol with an ester to form a product alcohol and a product ester, i.e., replacing the alcohol group in the ester reactant with a different alcohol. Alcohols could be present as products of biodiesel oxidation. Higher molecular weight alcohols have also been studied as oxygenated diesel-range fuel components (Muinos et al., 2017). The addition of acid (e.g. methanolic $\mathrm{HCl}$ ) or base (e.g. sodium methoxide in methanol) catalysts in the alcoholysis of triacylglycerols to produce biodiesel fuels is well known. The possibility that alcoholysis, in the absence of added acid or base catalysts, could occur between a FAME and an alcohol product of
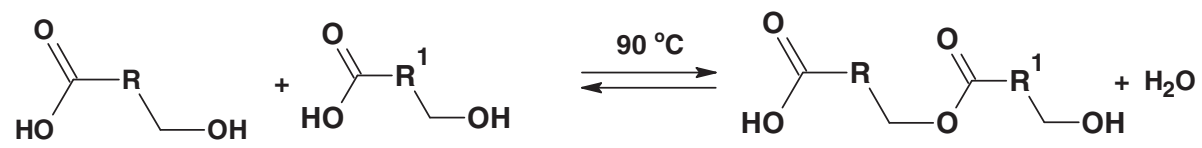

Reaction 1 Polymeric ester formation (reactions of carboxylic acids with alcohols) 
<smiles>CCPC(=O)OCC#CCCCCCCC(=O)OC[PH2+]CO</smiles>

Biodiesel FAME

Reaction 2 Alcoholysis (reaction of alcohols with esters)

FAME oxidation was proposed (Formo, 1954). A hypothetical example is given in Reaction 2, showing a biodiesel FAME reacting with the alcohol functional group of another molecule to form a larger molecule and methanol.

To test the hypothesis that alcoholysis reactions can occur with biodiesel under the aforementioned aging conditions, experiments were conducted allowing hexadecanol and methyl stearate (at equal molar concentrations) to react under the same conditions. These two reactants were chosen because they give products that can be assigned unambiguously to alcoholysis and esterification reactions. Figure 3 (black symbols) shows details of the reaction of hexadecanol with methyl stearate. In this experiment, a slow formation of hexadecyl stearate was observed over 45 days (Fig. 3, top panel). The products of the alcoholysis reaction are hexadecyl stearate and methanol. Under these conditions $\left(90^{\circ} \mathrm{C}\right.$, aeration), methanol would be quickly stripped from solution, driving the equilibrium reaction toward the hexadecyl stearate product.

In this experiment, hexadecyl palmitate formation was also observed (Fig. 3, top panel), albeit at a much slower rate (about $<1 \%$ of hexadecyl stearate formation). This additional product is attributed to the esterification reaction of hexadecanol with palmitic acid (hexadecanoic acid), the latter presumably formed from hexadecanol oxidation under these conditions. Over the first 45 days, TAN (Fig. 3, lower panel) remained at very low levels $\left(\sim 0.25[\mathrm{mg} \mathrm{KOH}] \mathrm{g}^{-1}\right)$ relative to oxidation experiments with biodiesel (typically $\sim 30[\mathrm{mg} \mathrm{KOH}] \mathrm{g}^{-1}$ ). The difference is due to the lack of polyunsaturated FAME (which are much more reactive than methyl stearate) and possibly because any acids produced could quickly react with hexadecanol.

At day 45 of the same experiment (Fig. 3, top panel), palmitic acid (13 mol.\%) was intentionally added, resulting in more rapid production of hexadecyl stearate (alcoholysis), indicating that palmitic acid and presumably other carboxylic acids can catalyze the alcoholysis reaction. Hexadecyl palmitate was simultaneously produced via esterification of the added palmitic acid with hexadecanol. Because both reactions involve hexadecanol, the experiment was terminated when hexadecanol was fully consumed. While the acid-catalyzed alcoholysis reaction proceeded faster than esterification, their rates cannot be directly compared because palmitic acid was present at lower concentration than methyl stearate.
Immediately after the palmitic acid was added on day 45 (with TAN increasing correspondingly), TAN dropped due to esterification of the palmitic acid with hexadecanol (Fig. 3, lower panel). After 7 days (day 52 overall), TAN started increasing suggesting that thermo-oxidative
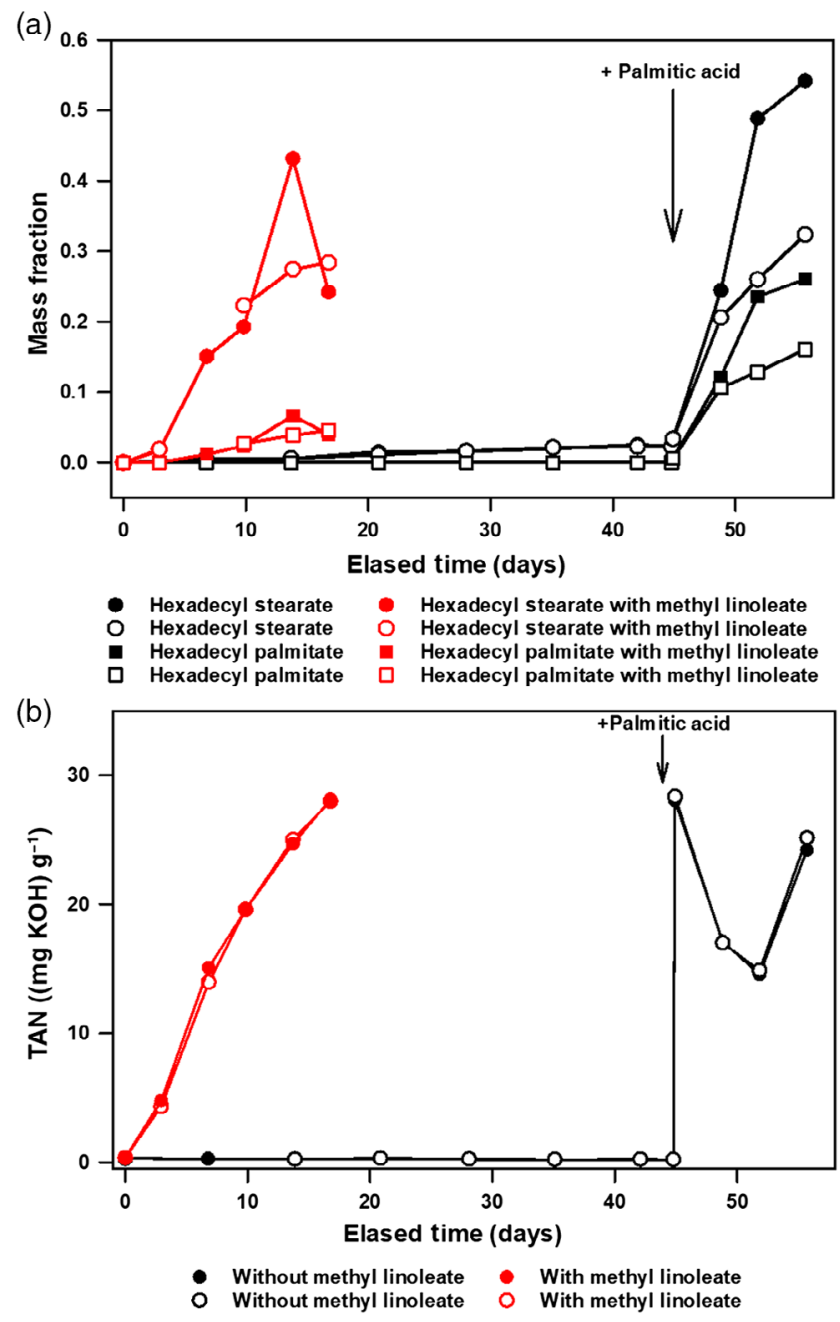

Fig. 3 Alcoholysis reaction of hexadecanol with methyl stearate initially at equimolar concentrations, with (red symbols) and without (black symbols) 9 mol.\% methyl linoleate. Top: ester products, hexadecyl stearate (circles) and hexadecyl palmitate (squares). Bottom: TAN. Results for duplicate experiments are shown as open and filled symbols. Experiment conducted at $90^{\circ} \mathrm{C}$ with aeration. Palmitic acid (13 mol.\%) was added at day 45 . Experiments were terminated when hexadecanol was fully consumed 
degradation reactions had initiated (presumably of hydrocarbon chains).

These results may help explain preliminary alcoholysis experiments (data not shown) in which the alcoholysis product was formed rapidly, but only after a lag time of 14-21 days. Despite some variability in lag time between replicates, the onset of alcoholysis coincided with the onset of rapid TAN formation. Carboxylic acids can be formed from the oxidation of the aliphatic side chains of the reactants, although the rate is certainly slower than at allylic reactive sites in unsaturated FAME (Chuck et al., 2012; de Carvalho et al., 2016; Waynick, 2005). The dramatic increase in the formation of the alcoholysis product coinciding with rapid TAN formation is consistent with carboxylic acids acting as an in-situ catalyst in the alcoholysis reaction. This set of experiments suggests that alcoholysis, especially in the presence of newly generated carboxylic acids, is a viable reaction of methyl esters with alcohols formed during the thermo-oxidative degradation of biodiesel fuel.

To further test the hypothesis that FAME oxidation products (e.g., carboxylic acids) can catalyze the alcoholysis reaction in this experiment, the hexadecanol/methyl stearate experiment was repeated while adding methyl linoleate (9 mol.\%) at the start of the experiment (Fig. 3, red symbols). Methyl linoleate, the most abundant FAME in SME biodiesel, oxidizes more rapidly than saturated FAME and was depleted to only $10 \%$ of the initial concentration after 3 days. As seen in Fig. 3, the presence and presumed thermo-oxidative degradation of the methyl linoleate led to more rapid formation of both hexadecyl stearate and hexadecyl palmitate than without methyl linoleate. TAN (Fig. 3, lower panel) rapidly increased with essentially no lag time, whereas the alcoholysis and esterification products started forming after a much shorter lag time (3 days) than without methyl linoleate. The rate of hexadecyl stearate formation (alcoholysis) was similar to that with palmitic acid added. In contrast, hexadecyl palmitate formation (esterification) was considerably slower than with added palmitic acid. In the absence of any added palmitic acid, palmitic acid would have only been generated from the oxidation of hexadecanol.

The relationship between the formation of acids and the product of the alcoholysis reaction was explored by plotting the formation of hexadecyl stearate versus TAN. As seen in Fig. 4, the dependence of the observed formation of hexadecyl stearate on TAN can be accounted using a sigmoidal model function. A sigmoidal function was chosen as a model for this reaction because the products would form slowly at first when the concentration of carboxylic acids are low, the rate would increase as more carboxylic acids were generated and the rate would slow due to consumption of reactants. A similar plot was not generated for

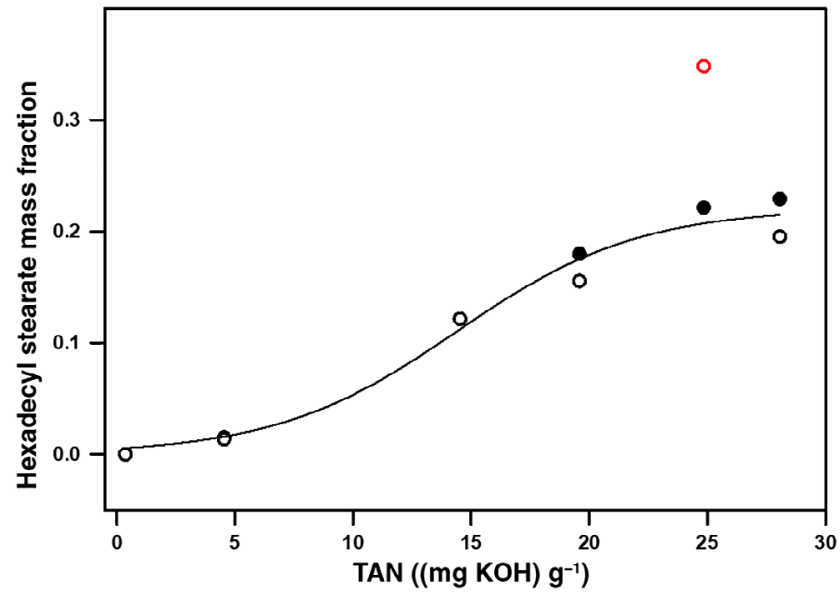

Fig. 4 Hexadecyl stearate formation as a function of TAN from the reaction of hexadecanol and methyl stearate initially at equimolar concentrations and containing 9 mol.\% methyl linoleate. Experiment conducted at $90{ }^{\circ} \mathrm{C}$ with aeration over 16 days. Acids are initially formed from the oxidation of methyl linoleate. Results for duplicate experiments are shown as open and filled symbols. The line is the best fit to a sigmoidal curve $\left(r^{2}=0.98\right)$. One outlier (open red circle) was not included in the fit of the data

the reaction of hexadecanol and methyl stearate because of the long lag time needed for acid formation and the subsequent addition of palmitic acid. These data (Fig. 4) give additional support for the hypothesis that carboxylic acids act as catalysts in the alcoholysis reactions. Together, these experiments demonstrate that alcohols and carboxylic acids, formed from the thermo-oxidative degradation of biodiesel fuel, can react to form new esters (Figs. 2 and 3). In addition, alcohols can react with methyl esters to form different esters that will be larger than methyl esters (Figs. 3 and 4).

Carboxylic acids, formed in-situ from the oxidation of biodiesel, have been reported to act as a catalyst in the alcoholysis reaction (Otton and Ratton, 1988; Salmi et al., 2004). Otton and Ratton suggested that carboxylic acids act as catalysts in both esterification and alcoholysis reactions (Otton and Ratton, 1988). Their work monitored the reactions of model alcohols (e.g., heptanol), esters (e.g., heptyl benzoate), and a carboxyl acid (benzoic acid) at temperatures greater than $150^{\circ} \mathrm{C}$ in a large excess of the alcohol (Otton and Ratton, 1988). Their data suggest that the alcoholysis reaction does not occur except in the presence of a carboxylic acid. Otton and Ratton reported that the rate of ester formation reactions was 2-3 times greater than the rate of alcoholysis reactions at equimolar concentrations of the reactants (Otton and Ratton, 1988). Despite this, the reaction of alcohols with FAME may also be important because FAME would generally be present at much higher concentration than the acid oxidation products. For example, SME biodiesel aged under these conditions eventually 


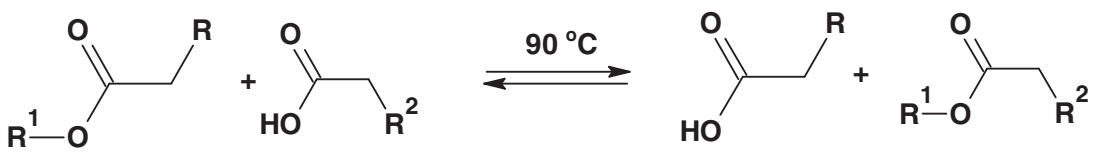

Reaction 3 Acidolysis (reaction of carboxylic acids with esters)

yielded a TAN of $30(\mathrm{mg} \mathrm{KOH}) \mathrm{g}^{-1}$ (Ball et al., 2018a), which assuming the carboxylic acid molecular weight approximates that of decanoic acid, gives a 6:1 concentration ratio of FAME to carboxylic acids. Both reactions are driven by volatilization of one of the products; the alcoholysis reaction with FAME produces methanol, while esterification of acids and alcohols formed from biodiesel oxidation generates water. These results suggest that alcoholysis of methyl esters to form new esters are likely to be a significant reaction for alcohols formed during the thermo-oxidative degradation of biodiesel.

\section{Acidolysis}

Acidolysis of an ester is the equilibrium reaction of a carboxylic acid and an ester to form a different ester and carboxylic acid (i.e., replacing the carboxylic acid group in the ester reactant with another carboxylic acid; Reaction 3). To investigate whether acidolysis could occur at relevant rates under these aging conditions, stearic acid and methyl palmitate (at equal molar concentrations) were allowed to react, with the expected products being methyl stearate and palmitic acid. Over 35 days, small amounts of both products were observed, with product concentrations reaching approximately $1-2 \%$ of the reactant concentrations (Table 2) despite the high concentration of stearic acid $(50 \mathrm{~mol} . \%)$. Whereas the equilibrium reaction of these model compounds was not driven toward product formation as neither of the products are significantly volatile, the reaction might be driven in other cases if one product was sufficiently volatile (e.g., acetic acid or methyl butyrate). These data suggest that acidolysis reactions may be occurring in the aforementioned biodiesel aging studies but

Table 2 Acidolysis products from the reaction of stearic acid with methyl palmitate

\begin{tabular}{lcc}
\hline $\begin{array}{l}\text { Elapsed } \\
\text { time } \\
\text { (days) }\end{array}$ & $\begin{array}{c}\text { Methyl stearate } \\
\text { \% of initial methyl } \\
\text { palmitate peak area) }\end{array}$ & $\begin{array}{c}\text { Palmitic acid } \\
\text { \% of initial stearic } \\
\text { acid peak area) }\end{array}$ \\
\hline 0.08 & 0.34 & 0.05 \\
1 & 0.42 & 0.06 \\
2 & 0.37 & 0.06 \\
3 & 0.37 & 0.05 \\
35 & 1.10 & 2.3 \\
\hline
\end{tabular}

likely at a relatively slow rate compared to direct ester formation and alcoholysis. Otton and Ratton, using p-toluic acid and heptyl benzoate, found that the rate of acidolysis was about $10 \%$ of the rate of ester formation between the corresponding alcohol and carboxylic acid (Otton and Ratton, 1988). While carboxylic acids are reactants in acidolysis, it is not known if they also catalyze this reaction.

\section{Ester Exchange}

Ester exchange reactions are another class of equilibrium reactions that potentially occur between two esters to form two different esters (i.e., exchanging the two alcohol groups, or equivalently the two carboxylic acid groups, between the two ester reactants; Reaction 4). This reaction would result in no identifiable change in composition for the initial biodiesel FAME mixture (it would exchange methanol for methanol). However, ester exchange reactions could result in composition changes after thermo-oxidative degradation of the FAME mixture generates a variety of esters with different alcohol and acid components.

The relevance of this reaction under the aging study conditions was evaluated by allowing two model ester compounds, ethyl palmitate and methyl stearate (at equal molar concentrations), to react, with the expected exchange products being ethyl stearate and methyl palmitate. After a 35-day reaction period, no evidence of the expected products was detected by GC-FID (Table 3), suggesting that ester exchange reactions (between FAME and/or other esters) are not likely to be a significant reaction under the aging conditions used here. For the reaction of these model compounds, the equilibrium reaction was not driven toward product formation as neither of the products are significantly volatile. The reaction might be driven in other cases if one of the product esters was sufficiently volatile (e.g., methyl butyrate). While catalysis by acids was not explicitly investigated, no ester exchange was observed despite significant amounts of acids being generated during the 35-day reaction period (Table 3).

\section{Oxidation Reactions}

While not involving the ester functional group, oxidation of the hydrocarbon chain in FAME occurs and contributes 


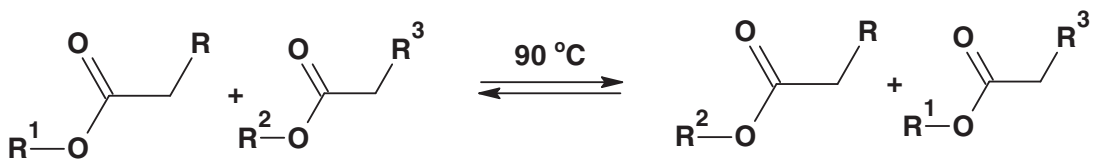

Reaction 4 Ester exchange (reaction between two esters)

Table 3 Ester exchange products from the reaction of methyl stearate and ethyl palmitate

\begin{tabular}{lccc}
\hline $\begin{array}{l}\text { Elapsed } \\
\text { time } \\
\text { (days) }\end{array}$ & $\begin{array}{c}\text { Ethyl stearate } \\
\text { (\% of initial methyl } \\
\text { stearate peak area) }\end{array}$ & $\begin{array}{c}\text { Methyl palmitate } \\
\text { (\% of initial ethyl } \\
\text { palmitate peak area) }\end{array}$ & $\begin{array}{c}\text { TAN } \\
(\mathrm{mg} \\
\mathrm{KOH} / \mathrm{g})\end{array}$ \\
\hline 0.08 & $\mathrm{ND}$ & $\mathrm{ND}$ & 1.1 \\
7 & $\mathrm{ND}$ & $\mathrm{ND}$ & 1.1 \\
14 & $\mathrm{ND}$ & $\mathrm{ND}$ & 1.9 \\
21 & $\mathrm{ND}$ & $\mathrm{ND}$ & 9.9 \\
28 & $\mathrm{ND}$ & $\mathrm{ND}$ & 19.3 \\
35 & $\mathrm{ND}$ & $\mathrm{ND}$ & 33.4 \\
\hline
\end{tabular}

$\mathrm{ND}$, not detected.

to the reactions involving the ester functional groups. Oxidation is relatively rapid for unsaturated FAME and the resulting products are both reactants and in some cases catalysts for alcoholysis, ester formation, and acidolysis reactions.

Saturated FAME may also be susceptible to thermooxidative degradation, albeit slowly and/or with an extended lag time, in these ester-focused experiments. To investigate this further, methyl stearate was allowed to oxidize under the same aging conditions as in the other experiments (Fig. 5). As in the alcoholysis experiments, there was a lag time before evidence of significant oxidation was

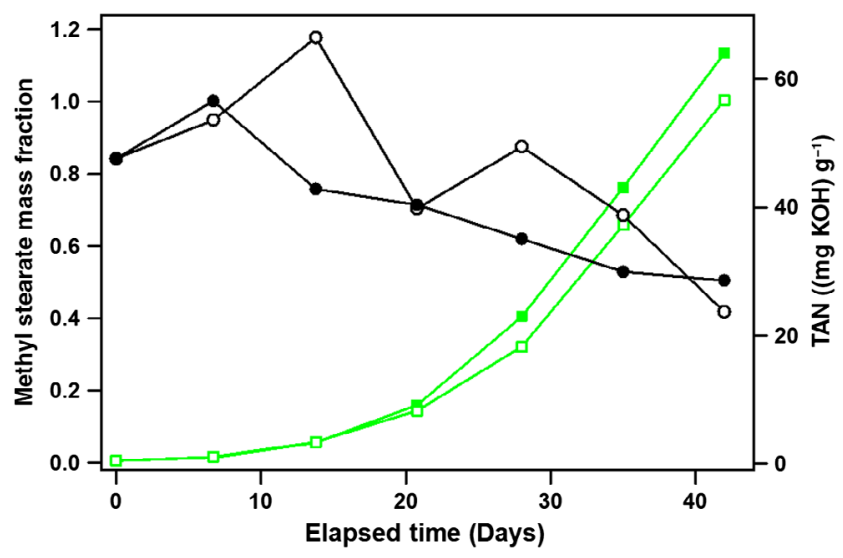

Fig. 5 Oxidation of methyl stearate at $90^{\circ} \mathrm{C}$ with aeration. Methyl stearate (black circles) and TAN (green squares) were measured for 42 days. Results for duplicate experiments are shown as open and filled symbols observed in the form of increasing TAN. After 42 days, the TAN reached $\sim 60(\mathrm{mg} \mathrm{KOH}) \mathrm{g}^{-1}$ and approximately half of the methyl stearate appeared to have reacted, with numerous product peaks detected by GC-FID. The existence of a lag time suggests that these thermo-oxidative degradation reactions involve chain reactions involving oxidation products.

\section{Conclusions}

Four reactions involving ester functional groups (as reactants and/or products) were investigated that are relevant in biodiesel thermo-oxidative degradation studies. These reactions could involve biodiesel FAME and their oxidation products as reactants, and could play roles in determining the resulting products that are formed, including high molecular weight polyesters. These reactions were experimentally evaluated using model compounds under conditions of prior biodiesel thermo-oxidative degradation studies $\left(90^{\circ} \mathrm{C}\right.$ with aeration) (Ball et al., 2018a; Østerstrøm et al., 2016).

Of the four ester reactions, ester formation from alcohols and acids (known biodiesel oxidation products) occurred at the highest rate. The alcoholysis reaction, involving replacement of one alcohol for another within an existing ester, occurred at a somewhat slower rate and was only observed in the presence of carboxylic acids (either directly added or after significant oxidation and TAN formation had occurred), consistent with catalysis by carboxylic acids (Otton and Ratton, 1988). The formation of new esters is consistent with prior biodiesel oxidation studies (Otton and Ratton, 1988). Both ester formation and alcoholysis were driven by stripping of a volatile product (water or methanol, respectively). Acidolysis was observed to occur, but at a much slower rate than ester formation and carboxylic acid-catalyzed alcoholysis (Otton and Ratton, 1988). Ester exchange reactions were not observed with the model compounds.

Together, these experiments suggest a set of complex inter-related reactions originating from FAME and their thermo-oxidative degradation products that can contribute to the formation of new esters with potentially higher molecular weight and, therefore, leading to increased viscosity. Carboxylic acids and alcohols, known biodiesel 
oxidation products, played critical roles in many aspects of these reactions. Alcohols and carboxylic acids, formed from the oxidation of biodiesel fuel, can react to form new esters. Alcohols can also react with methyl esters to form different esters. The alcohol functional group can also oxidize to a carboxylic acid. Ester formation and alcoholysis reactions are catalyzed by the carboxylic acids generated from FAME oxidation (with unsaturated FAME being most reactive) and alcohol oxidation. Based on these results, alcoholysis and esterification are now believed to have been the most prevalent of the three alcohol reactions in our prior biodiesel aging studies (Ball et al., 2018a; Østerstrøm et al., 2016) due to the relative abundance of available esters and acids.

The fact that alcohols are not found in large amounts as oxidation products in biodiesel oxidation studies may be due to the titration of alcohols by esterification reactions and alcoholysis reactions with methyl esters (forming methanol that may evaporate), as well as conversion to aldehydes and acids via oxidation reactions. Alcohols are likely to be the limiting reactant in these reactions, as carboxylic acids and esters are generally always present in relative abundance during these oxidation studies.

Saturated FAME, while understood to be considerably less reactive via oxidation as compared to unsaturated FAME, were shown to be susceptible to carboxylic acid-catalyzed alcoholysis and, to a lesser extent, acidolysis. Saturated FAME also appear to be susceptible to alkyl chain oxidation.

FAME thermo-oxidative degradation reactions and these ester-specific reactions, individually and collectively, have the potential to generate a diverse array of products. The ester reactions have the potential to generate larger molecules that increase viscosity, both from exchange of smaller groups for larger groups and from linkages by polyfunctional oxidation products (e.g., dicarboxylic acids, dialcohols, and hydroxycarboxylic acids) to form polyesters.

Conflict of Interest The authors declare that they have no conflict of interest.

\section{References}

Ball, J. C., Anderson, J. E., Pivesso, B. P., \& Wallington, T. J. (2018a) Oxidation and polymerization of soybean biodiesel/petroleum diesel blends. Energy \& Fuels, 32:441-449.

Ball, J. C., Anderson, J. E., \& Wallington, T. J. (2018b) Depolymerization of polyester polymers from the oxidation of soybean biodiesel. Energy \& Fuels, 32:12587-12596.
Barkenbus, C., Roswell, C. A., \& Mitts, A. E. (1940) The equilibrium constants for the systems alkyl formates and alkyl acetates with stearic acid. Journal of the American Chemical Society, 62: 1251-1253.

Chuck, C. J., Bannister, C. D., Jenkins, R. W., Lowe, J. P., \& Davidson, M. G. (2012) A comparison of analytical techniques and the products formed during the decomposition of biodiesel under accelerated conditions. Fuel, 96:426-433.

de Carvalho, A. L., Cardoso, E. A., da Rocha, G. O., Teixeira, L. S. G., Pepe, I. M., \& Grosjean, D. M. (2016) Carboxylic acid emissions from soybean biodiesel oxidation in the EN14112 (Rancimat) stability test. Fuel, 173:29-36.

Fang, H. L., \& McCormick, R. L. (2006) Spectroscopic study of biodiesel degradation pathways (SAE Technical Paper No. 2006-01-330).

Formo, M. W. (1954) Ester reactions of fatty materials. Journal of the American Oil Chemists' Society, 31:548-559.

Knothe, G., Van Gerpen, J. H., \& Krahl, J. (2005) Oxidative stability of biodiesel. In The biodiesel handbook (1st ed., pp. 130-134). Champaign, IL: AOCS Press.

Koskikallio, J. (1969) Alcoholysis, acidolysis and redistribution of esters. In S. Patai (Ed.), Carboxylic acids and esters (pp. 104-136). Hoboken, NJ: John Wiley \& Sons.

Morrison, R. T., \& Boyd, R. N. (1992) Organic chemistry (6th ed., pp. 658-700). Upper Saddle River, NJ: Prentice Hall.

Muinos, M., Soloiu, V., Moncada, J., Gaubert, R., Molina, G., \& Williams, J. (2017) Experimental investigation on the combustion and emissions characteristics of n-butanol/GTL and n-butanol/diesel blends in a single-cylinder MD-CI engine (SAE Technical Paper No. 2017-01-0719). SAE.

Østerstrøm, F. F., Anderson, J. E., Mueller, S. A., Collings, T., Ball, J. C., \& Wallington, T. J. (2016) Oxidation stability of rapeseed biodiesel/petroleum diesel blends. Energy \& Fuels, 30: $344-351$.

Otton, J., \& Ratton, S. (1988) Investigation of the formation of poly(ethylene terephthalate) with model molecules: Kinetics and mechanism of the catalytic esterification and alcoholysis reactions. I. Carboxylic acid catalysis (monofunctional reactants). Journal of Polymer Science Part A: Polymer Chemistry, 26:2183-2197.

Sallee, E., Hopper, T., Link, W., Walker, R., Firestone, D., \& Mehlenbacher, V. (2004) AOCS Cd 3d-63. Official methods and recommended practices of the AOCS. Champaign, IL: AOCS Press.

Salmi, T., Paatero, E., \& Nyholm, P. (2004) Kinetic model for the increase of reaction order during polyesterification. Chemical Engineering and Processing_Process Intensification, 43:1487-1493.

SDBSWeb. (2018) Spectral database for organic compounds. National Institute of Advanced Industrial Science and Technology. Retrieved from http://sdbs.db.aist.go.jp/sdbs/cgi-bin/direct_frame_ top.cgi

TGSC. (2018) TGSC information system. Retrieved from http://www. thegoodscentscompany.com/search $2 . \mathrm{html}$

Waynick, J. A. (2005) Characterization of biodiesel oxidation and oxidation products: Technical literature review. Task 1 results (CRC AVFL-2b). Alpharetta, GA: Coordinating Research Council.

Wexler, H. (1964) Polymerization of drying oils. Chemical Reviews, 64:591-611.

Wright, H. J., Segur, J. B., Clark, H. V., Coburn, S. K., Langdon, E. E., \& DuPuis, R. N. (1944) A report on ester interchange. Oil \& Soap, 21:145-148. 